\title{
(t)
}

\section{A (CON)VOCAÇÃO DO TRABALHO FEMININO DIANTE DAS MUDANÇAS DO MUNDO TRABALHO: O CARE EM EVIDÊNCIA'}

\author{
THE CONVOCATION OF WORK FEMALE BEFORE THE WORLD CHANGES \\ WORK: THE CARE IN EVIDENCE \\ Fernanda Caldas de Azevedo \\ Rachel Gouveia Passos ${ }^{3}$
}

\section{RESUMO}

O presente artigo tem por finalidade apreender a relação entre a conjuntura macroestrutural do mundo do trabalho em face da reestruturação produtiva, com foco no processo de precarização acentuado quando tratado a partir da divisão social e sexual do trabalho. Como uma expressão dessa conjuntura, o trabalho do cuidado - care - tem sido convocado por parte do mercado e das políticas públicas, enquanto resposta para a promoção do cuidado em razão do aumento da participação das mulheres na esfera produtiva, através de profissionais para a promoção do cuidado. Assim, problematizamos a emergência dessa ocupação frente às transformações econômicas, políticas e sociais, especificamente, na realidade brasileira.

Palavras-chave: Trabalho. Precarização. Care. Gênero.

\section{ABSTRACT}

This article aims to grasp the relationship between macro-structural context of the working world in the face of productive restructuring, focusing on the process of marked instability when treated from social and sexual division of labor. As an expression of this situation, the work of care - care - has been

1 O presente artigo compõe as pesquisas de doutorado de ambas as autoras que se encontram em desenvolvimento no Programa de Estudos Pós-Graduados em Serviço Social da Pontifícia Universidade Católica de São Paulo (PUC/SP).

2 Assistente Social e doutoranda em Serviço Social pela PUC/SP. Bolsista CNPQ.

3 Assistente Social e doutoranda em Serviço Social pela PUC/SP. Bolsista CAPES. 


\section{temporollis}

summoned by the market and public policy, as a response to the promotion of caution against the increased participation of women in the productive sphere, from professionals to promote care. Thus, we question the emergence of this occupation in the face of economic, political and social, specifically, changes in the Brazilian reality.

Keywords: Work. Precariousness. Care. Genre.

Submetido: 26/08/2015.

Aceito: 26/11/2015.

\section{Introdução}

O presente artigo parte da reestruturação produtiva, compreendida como uma das alternativas do capital para sair da crise estrutural que assolou o mundo nos anos 1970 e 1980, apontando para uma nova realidade. As repercussões da reestruturação produtiva aparecem de diferentes formas, se adaptando a realidade conjuntural de cada país. Como aspecto comum, apontamos a precarização, acentuada quando tratamos da divisão sociossexual ${ }^{4}$ do trabalho, aqui sinalizada especificamente pelo care, atividade essa executada principalmente pelas mulheres, onde tem tido um significativo crescimento por meio da mercantilização, via setor de serviços.

Trabalhamos, com base no care, a relação entre as categorias trabalho, precarização e gênero. Para tanto, partimos do conceito de trabalho embasado na vertente teórico-crítica marxista. Contudo, foi a partir do conceito ampliado de trabalho apresentado por Hirata e Kergoat (2007), que tratamos da divisão social e sexual do trabalho enquanto reprodução do sistema de gênero que é apropriado e reproduzido pela sociabilidade burguesa no cotidiano. Portanto, as relações sociais e a divisão sexual do trabalho são indissociáveis, sendo nessa indissociabilidade, que se torna possível a ampliação do conceito de trabalho.

A relação com a precarização encontra-se nas formas de trabaIho que aparecem como lógica da reconstrução e de valorização do capital. Essa discussão aparece interligada com o debate de gênero à medida que através do care localizamos a hierarquização e as relações de opressão que são perpetuadas pela submissão do trabalho do cuidado, efetuado pelas mulheres na esfera da reprodução.

4 Essa terminologia adotada ao longo do texto foi introduzida por Cláudia Mazzei Nogueira (2013). 
A finalidade está em fundamentar algumas das implicações que a reestruturação produtiva imprimiu e refletiu no mercado de trabalho e nas condições da divisão sociossexual do trabalho tendo em vista o care. Devido à precarização do trabalho feminino, as mulheres com menos acesso a formação profissional ocupam espaços de trabaIho que são desvalorizados por serem vistos enquanto não produtores de valor, portanto, esse fazer não necessita de formação e sim, de qualidades advindas das características do gênero feminino. Assim, será problematizada, através de revisão e análise bibliográfica, a convocação do care enquanto uma ocupação que vem sendo demandada pelo mercado de trabalho e pelas políticas públicas para provimento do cuidado na esfera reprodutiva.

\section{Mundo do trabalho e reestruturação produtiva}

As transformações advindas com a reestruturação produtiva, no século $X X$, consolidaram novas relações de trabalho a partir das desregulamentações e das estratégias de valorização do capital, pela ampliação de extração de mais valia, por meio da precarização das condições de trabalho.

Segundo Lazzareschi (2015), os processos de precarização, de flexibilização e de desregulamentação, são diferentes, mas todos fazem parte das reformas do Estado, descompromissado com a preservação dos padrões de regulação keynesiana dos mercados. Todo este movimento põe em risco a conquista dos direitos básicos dos trabalhadores.

A autora exemplifica apontando que regulamentação não evita a precarização, pois no Brasil existem 922 artigos de leis a reger o mercado de trabalho e ainda existe trabalho escravo, informal e de remuneração inferior ao salário mínimo. As diferentes formas de trabalho consideradas precárias foram regulamentadas no Brasil.

A precarização das relações de trabalho agrava a situação dos trabalhadores no mercado de trabalho, agora mais restrito e exigente devido à reestruturação produtiva que se traduz em uma lógica de redução dos custos da produção com introdução da tecnologia e, em decorrência, com a redução dos postos de trabalho e com a intensificação de relações de trabalho intermitentes.

De acordo com Lazzareschi (2015), as novas relações de trabaIho que surgiram no contexto da crise da economia mundial, inicia- 


\title{
temporollis
}

ram-se na segunda metade da década de 1960 com o esgotamento do paradigma taylorista/fordista por sua rigidez tecnológica e organizacional que inviabiliza a inovação de produção com sua produção padronizada em massa, instabilidade dos mercados, novos padrões de consumo a exigir inovação de produção, a globalização financeira com o fim do Tratado de Bretonwood e a regulamentação dos mercados de trabalho em vários países industrializados e as pressões sindicais que aumentaram os salários ao longo dos "Anos Dourados" e exigiram benefícios sociais.

\begin{abstract}
Ainda que regulamentado e contratado, a degradação do trabalho na sociedade taylorizada e fordizada estava estampada em sua mecanização, parcelização, manualização, alienação e, no limite, desantropomorfização. (ANTUNES, 2008, p.20).
\end{abstract}

Os novos paradigmas trazidos pela reestruturação produtiva, tendo como expoente o toyotismo, intensificaram as formas de exploração do trabalho. O asseveramento desse processo ocorre mediado pela implementação de formas mais eficientes de gestão e controle do trabalho, podendo-se acrescentar a tecnologia como um desses mecanismos. $\mathrm{O}$ trabalhador se vê pressionado a assimilar as exigências de qualificação e a assumir novas funções, intensifica-se 0 ritmo do trabalho e a própria subjetividade do trabalhador tornandose alvo do capital.

\begin{abstract}
Essa transformação estrutural teve forte impulso após as vitórias do neoliberalismo, quando um novo receituário, um novo desenho ideo-político se apresentou como alternativa de dominação em substituição ao Estado-Providência. Começava a se expandir uma outra pragmática, que se articulou intimamente com a reestruturação produtiva em curso à escala global. (ANTUNES, 2008, p. 20).
\end{abstract}

A subsunção real do trabalhador está ligada a alienação, uma vez que o conhecimento do trabalhador é repassado às máquinas assumindo um processo racional de produção. Esse modelo estrutural exige um novo tipo de trabalhador, que segundo Antunes (2008, p. 21) deve ser

[...] 'polivalente', 'multifuncional' [...] não é aquele fundamentado na especialização taylorista e fordista, mas o que floresceu na fase da 'desespecialização multifuncional', do 'trabalho multifuncional', que em verdade expressa a enorme intensificação dos ritmos, tempos e proces- 


\section{tempordils}

sos de trabalho. E isso ocorre tanto no mundo industrial, quando nos serviços.

Lazzareschi (2015) afirma que as soluções advindas da crise são, dentre outras, a globalização comercial e a reestruturação produtiva, que no Brasil teve seu ponto alto na década de 1980 expressando-se em altos índices inflacionários, em baixos índices de investimento, no altíssimo número de desemprego e na forte pressão dos credores internacionais para o pagamento da dívida externa. Foram cinco planos econômicos, quatro deles fracassados: Plano Cruzado (1986), Plano Bresser (1987), Plano Verão (1989), Plano Collor (1990) e Plano Real (1993). Com o último foi possível o controle da inflação e a retomada do crescimento econômico interrompido com a crise da Ásia (1997). Nesses anos de crise foram aceitas oficialmente novas relações de trabalho como alternativa a crise, configurando-se o processo de flexibilização das relações de trabalho.

Ainda segundo a autora, essa globalização da produção atinge os trabalhadores pelas seguintes razões: 1- redução dos postos de trabalho a partir do rígido controle dos procedimentos operacionais para eliminar unidades repetitivas e/ou ineficientes; 2- desestruturação dos mercados de trabalho com a terceirização da produção e da prestação de serviços; 3- produção orientada pela demanda (banco de horas e contrato temporário); 4- desenvolvimento do sentimento de insegurança por parte dos trabalhadores; 5 - concentração do poder sem centralização do poder; 6- exigência de novos saberes (empregabilidade, capacidade de candidatar-se a um emprego passou a ser responsabilidade do empregado) e 7- redução do poder de barganha dos sindicatos.

Para Antunes (1999), dentre as tendências do mundo do trabaIho, podemos destacar, a expansão dos assalariados médios e de serviços submetidos cada vez mais à racionalidade do capital. $O$ aspecto que o autor usa para destacar isso é o assalariamento, que aproxima os trabalhadores da esfera do serviço aos do industrial. Dentre outras formas contemporâneas do trabalho, o autor aponta a expansão do trabalho social, mais complexificado, socialmente combinado e mais intensificado em seus ritmos e processos.

Pela redução do trabalho vivo e ampliação do morto, o capital aumenta a utilização e a produtividade do trabalho de modo a intensificar a extração de sobretrabalho. A ideia é reduzir a parte variável 


\section{temporollis}

(custo da força de trabalho) e a necessidade de expandir a parte constante, já que não se pode eliminar o trabalho vivo porque é com ele que se integraliza o ciclo reprodutivo pelo consumo. Articulação entre trabalho vivo e morto é condição para que o sistema produtivo do capital se mantenha.

A classe trabalhadora trabalha muito mais por consequência da redução do trabalho vivo pelo capital, da crescente apropriação da dimensão cognitiva do trabalho, da ampliação da desqualificação e da precarização do trabalho. E ao mesmo tempo, há um número crescente de trabalhadores que, mesmo em busca de qualquer atividade, encontram cada vez menos trabalho, isso numa escala mundial. Portanto, o trabalho estável reduziu-se notoriamente, enquanto isso, a classe trabalhadora cresceu e sofreu transformações tornando-se ainda mais complexa. Assim, diante de tantas mudanças torna-se necessário compreender as novas expressões da precarização no setor de serviços.

\section{Setor de serviços e precarização}

Ao abordar o trabalho a partir da vertente teórica marxista, o compreendemos como portador de duas dimensões: concreta e abstrata.

A segunda aparece pela extração de mais-valia, considerando não somente a produção de mais-valia, como também o circuito de valorização do capital. Neste circuito, o resultado pode vir pela forma corpórea, por exemplo, a produção industrial ou ainda, pela forma não corpórea, por exemplo, a esfera de serviços.

Segundo Marx (2004), no âmbito da teoria do valor-trabalho, o valor é explicado dada a quantidade do trabalho incorporada no processo de produção das mercadorias. Ainda para o autor, não é a materialidade do produto que define se determinada atividade econômica é produtiva. A definição de trabalho produtivo se dá pela forma independente do conteúdo material e tangível da mercadoria. O trabalho produtivo contribui para a formação de excedente na economia e a ausência de uma base material não impede que o serviço tenha valor, principalmente de uso.

Assim, do ponto de vista produtivo o importante é que se estabeleça uma relação capitalista de produção, ou seja, todos os serviços cujo processo produtivo se dê em bases capitalistas de produção são 


\section{tempordilis}

considerados produtivos independente do resultado tangível ou não.

Compreender a esfera dos serviços, teoricamente não é algo tão simples, há diversas teorias. Para fins deste artigo, consideramos que serviços não são úteis como coisa, mas como atividade, ou seja, o trabalho em serviços tem particularidades que limitam sua captura integral porque envolve conhecimento, qualificação e dimensão relacional. Marx aponta que os serviços também são assimilados pela produção de mais-valia e o trabalhador em serviços envolve atributos imanentemente humanos.

Segundo Silva e Meirelles (2006), o setor de serviços prima pela heterogeneidade e variedade, seja em termo das características de produto e processo, seja do ponto de vista das estruturas de mercado, heterogeneidade esta que se reflete no tratamento teórico dado ao setor.

Ainda segundo a autora, os processos de reestruturação produtiva têm colocado requisições ao trabalho no campo dos serviços sociais como estratégias de mecanização e racionalização. Como um dos exemplos, tem-se a diminuição das horas de trabalho e consequentemente dos postos de trabalho o que esbarra na questão de o fator humano ser indispensável, como já foi abordado.

Apresenta ainda estratégias de racionalização como incentivos para aumentar a produtividade dos trabalhadores, como maior controle sobre os horários de trabalho, encurtamento de períodos de descanso e, entre outros, dificuldade de estabelecer critérios de produtividade para prestação desses serviços.

Ao se considerar serviço como processo prestado e não como produto, desvela-se o cunho interativo entre profissional e usuário, portanto, um trabalho relacional. Marx (2004) salienta que o serviço não possui uma conformação objetiva e separada do seu prestador, na prestação de serviço deve-se considerar o protagonismo do prestador e do receptor do mesmo serviço.

Segundo Shütz e Mioto (2012), o fator humano presente nessa interseção revela as potencialidades dos serviços assistenciais. O setor de serviços representa um campo de mediações em que o profissional não é totalmente capturado e padronizado. Ainda segundo as autoras, a captura total do trabalhador de serviços não seria possível, devido a essa esfera relacional, mas sua condição de assalariado (vín- 


\section{temporalis}

culo institucional) cerceia sua autonomia.

Braverman (2012) aponta as razões para o rápido aumento da prestação de serviços tanto na empresa privada como nos setores públicos da economia: a conquista completa das atividades industriais, correspondendo à acumulação de capital nelas e a junção dessas reservas de trabalho e capital no terreno de novas indústrias; e, o crescimento das necessidades de serviços à medida que a nova forma de sociedade destrói as antigas formas de cooperação mútua social, comunitária e familiar.

Segundo Marx (2004), um serviço é nada mais que o efeito útil de um valor de uso, seja ele mercadoria ou trabalho. Braverman (2012) aponta que o trabalhador empregado pelo capital oferece o serviço diretamente ao consumidor, uma vez que a produção e consumo são simultâneos, os efeitos úteis do trabalho que não tomam forma de objeto. Os próprios efeitos do trabalho transformam-se em mercadoria. Quando o trabalhador não oferece esse trabalho diretamente ao usuário de seus efeitos, mas ao invés, vende-o ao capitalista, que o revende no mercado de bens, então temos o Modo de Produção Capitalista no setor de serviços.

Braverman (2012) destaca que o capitalista passou a pagar pessoas para efetuar serviços como atividade lucrativa - em larga escala - mercado universal - transformando em mercadoria toda forma de atividade do ser humano.

Ainda aponta que os serviços constituíram grande parcela na divisão social do trabalho por toda a era capitalista, mas não constituíram uma parte produtiva ou lucrativa senão recentemente. Porque essas atividades não eram efetuadas sob os auspícios do capital como capital.

Segundo Antunes (2007) e Braverman (2012), há uma transformação do trabalho improdutivo em produtivo, representando o movimento próprio do processo da criação da sociedade capitalista. As funções improdutivas produziram seus exércitos de assalariados com condições semelhantes às daqueles exércitos de trabalho organizado na produção. Tornaram-se outra forma de exploração (BRAVERMAN, 2012).

Considerando o trabalho como forma de realização do ser social objetivado pela produção e reprodução da sua existência, preci- 


\section{tempordilis}

samos pensar o trabalho inserido num contexto típico do Modo de Produção Capitalista, no qual o trabalho aviltado e degradado tornase estranhado.

Segundo Antunes (2007), o processo de trabalho se converte em meio e subsistência, a força de trabalho torna-se uma mercadoria cuja finalidade é produzir mercadorias. O que deveria ser a forma humana de realização do indivíduo reduz-se à única possibilidade de subsistência do despossuído. Precariedade e perversidade são características do trabalho no Modo de Produção Capitalista.

Na sociedade capitalista,

[...] o valor de uso (o produto do trabalho concreto) não serve para a satisfação das necessidades. Ao inverso, sua essência consiste em satisfazer as necessidades do não-possuidor. Ao trabalhador lhe é completamente indiferente o tipo de valores de uso por ele produzido, não tendo com eles nenhuma relação. O que desenvolve para satisfazer suas necessidades é, pelo contrário, trabalho abstrato: trabalha unicamente para manter-se, para satisfazer as meras necessidades 'necessárias'. (HELLER, 1986, p. 54).

Segundo Mészaros (1981, p. 76), “[...] um ser cuja essência não coincide diretamente com a sua individualidade". Assim, em lugar da consciência de ser social, têm-se o culto da privacidade, tem-se uma sociedade regida pelo capital, uma forma de objetivação do trabalho, onde as relações sociais estabelecidas entre os produtores assumem a relação entre os produtos do trabalho.

Antunes (2007) aponta que a racionalização da produção capitalista elimina as propriedades qualitativas do trabalhador, pela decomposição cada vez maior do processo de trabalho em operações parciais, operando-se uma ruptura entre o elemento que produz e o produto desse trabalho. E continua o autor, este é reduzido a um nível de especialização, que acentua a atividade mecanicamente repetida. E essa decomposição penetra no trabalhador no plano da consciência, a coisificação e a reificação, o trabalho estranhado converte-se em forte obstáculo à busca da omnilateralidade e plenitude do ser.

Este movimento aponta um novo problema que é a manipulação ideológica do trabalhador que ergue uma barreira no interior do sujeito entre a sua existência e uma vida rica de sentido, e este movi- 


\section{temporollis}

mento se estende para a esfera do consumo. Assim, as características do mercado de trabalho são expressões da vigência da lei do valor e as expressões da precarização são formas de o capital ampliar o seu valor. Portanto, cabe sinalizar que diante dessas novas configurações a figura feminina é convocada, de forma massiva, a inserir-se ativamente no mundo do trabalho, principalmente na esfera de serviços.

\section{Divisão sociossexual do trabalho}

A partir dos anos 1970 as feministas analisaram e teorizaram a divisão sexual do trabalho, avançando na análise da teoria crítica e dando-lhe um novo conteúdo acerca da relação mulher e trabalho, e assim, definindo trabalho doméstico enquanto trabalho. Portanto, foi nesse cenário, que segundo Kergoat (2009, p. 67), “[...] a divisão sexual do trabalho adquiriu [...] o valor de um conceito analítico."

De acordo com Hirata e Kergoat (2007, p. 596), a terminologia "divisão sexual do trabalho" aplica-se com base em duas acepções: "[...] a distribuição diferencial de homens e mulheres no mercado de trabalho, nos ofícios e nas profissões" e "[...] como ela se associa à divisão desigual do trabalho doméstico entre os sexos." Assim como as autoras destacam a segunda acepção em seu texto, será destacado neste item tal caminho e, deste modo, "[...] os processos mediante os quais a sociedade utiliza essa diferenciação para hierarquizar as atividades, e, portanto, os sexos, em suma, para criar um sistema de gênero."

O capitalismo perpetua-se nesse sistema de gênero, onde a exploração do capital sobre o trabalho hierarquiza e segmenta as funções, no intuito de subalternizar o trabalho executado pelas mulheres. De acordo com Campos e Teixeira (2010, p. 21) o gênero é assim visto como um "[...] elemento constitutivo das relações interpessoais e sociais na sociedade em geral. (Com isso) definem-se padrões quanto a posições, atitudes e comportamentos e práticas em geral." Essa subalternidade feminina se dá inicialmente no espaço doméstico e é perpetuada nas relações sociais, sendo de fundamental importância a padronização das relações no mundo do trabalho e na produção da riqueza.

Essa generalização da divisão sexual do trabalho para além do resultado das relações sociais entre os sexos, torna-se um sistema prioritário de sobrevivência da própria relação entre os sexos que fo- 
ram constituídos socialmente e historicamente. "Tem como características a designação prioritária dos homens à esfera produtiva e das mulheres à esfera reprodutiva e, simultaneamente, a apropriação pelos homens das funções com maior valor social." (HIRATA; KERGOAT, 2007, p. 599). Essa individualidade complexa reproduzida no cotidiano é absorvida subjetivamente, sendo ela resposta para os seus atos pautados nos valores desenvolvidos pelo gênero humano.

Compreendendo que a divisão sexual do trabalho é apropriada pela sociabilidade burguesa e reproduzida na individualidade em seu dia a dia, resultando na desigualdade dos sexos, é que destacamos dois princípios organizadores desse sistema retratados por Hirata e Kergoat (2007)5: o princípio de separação (existem trabalhos de homens e trabalhos de mulheres) e o princípio hierárquico (um trabalho de homem "vale" mais que um trabalho de mulher). Tais princípios estão relacionados com o conceito de relação social sexuada, "[...] que é correlativo ao de conceito de divisão sexual do trabalho" que busca romper com uma abordagem teórica em relação a papéis e funções (HIRATA, 2002, p. 275). Tanto para Kergoat quanto para Hirata as relações sociais sexuadas e a divisão sexual do trabalho são "duas expressões indissociáveis" e que constituem um sistema. É nessa indissociabilidade que as autoras ampliam o conceito de trabalho: ampliação do conceito de trabalho ao trabalho doméstico, ao trabalho não remunerado, ao trabalho informal.

Nesse sentido, o conceito de divisão sexual baseia-se em uma relação antagônica entre homens e mulheres. A divisão sexual do trabalho torna-se um aspecto da divisão social do trabalho na qual se identifica a hierarquização e a opressão de gênero demonstrando a indissociabilidade entre as relações entre homens e mulheres e a esfera da produção e reprodução. Essa teoria da divisão sexual constituise como "[...] alternativa aos paradigmas sociológicos que não levam em conta a 'sexualização' do social." (KERGOAT, 1995 apud HIRATA, 2002, p. 281).

Com as mudanças ocorridas no mundo do trabalho e da reestruturação produtiva, as mulheres neste cenário foram "convocadas" a assumir o campo da produção. A entrada maciça das mulheres na

5 Para as autoras esses "[...] princípios (de separação e hierárquico) encontram-se em todas as sociedades conhecidas e são legitimados pela ideologia naturalista, isto não significa, no entanto, que a divisão sexual do trabalho seja um dado imutável." (HIRATA; KERGOAT, 2007, p. 599-560). 


\section{temporollis}

indústria, nos anos 1970, foi denominada por Nogueira (2004), de "feminização do mundo do trabalho".

Essa inserção da mulher na esfera produtiva não veio desacompanhada de um movimento político. Ocorria nesse período a transformação dos padrões culturais e éticos que normatizavam os comportamentos entre homens e mulheres, intensificada pelo movimento feminista. Contudo, fatores econômicos marcaram essa (con) vocação das mulheres para inserirem-se no mercado de trabalho. Só que, com a inserção e participação das mulheres no mercado de trabalho, a desigualdade entre as relações sociais de sexo continuava a ser reproduzida em relação às ocupações.

Ao longo das décadas seguintes ocorreram transformações no mercado de trabalho direcionado para as mulheres, onde a globalização ${ }^{6}$ econômica e financeira trouxe uma série de repercussões a partir dos anos 1990 que puderam estabelecer oportunidades, mas também desafios. Nesse sentido, "[...] trata-se de um dos paradoxos da globalização, este aumento do emprego feminino remunerado acompanhado pela sua precarização e vulnerabilidade crescentes." (HIRATA, 2002, p.28)

Bruschini (2007) apresentou em seu estudo um panorama do trabalho feminino, dando destaque a intensidade e constância do crescimento da participação feminina no mercado de trabalho brasileiro, no período de 1993-2005. Os dados foram extraídos de indicadores do IBGE conforme o Censo Demográfico, identificando assim a População Economicamente Ativa (PEA) no período pesquisado. A autora identificou que em 1995 havia 40\% de mulheres na PEA, representando 27,8 milhões, que estavam ocupadas; para 59,6\% de homens na PEA, sendo 41,9 milhões, que estavam ocupados. Já no ano de 2005 , havia $43,5 \%$ das mulheres na PEA, sendo que 36,6 milhões se encontravam ocupadas; para $56,5 \%$ de homens na PEA, sendo que 50,4 milhões estavam ocupados.

$\mathrm{Na}$ "Pesquisa Nacional por Amostra a Domicílios Contínua" realizada pelo IBGE referente aos anos 2012 e 2013, pode ser identi-

6 "A globalização é a liberdade para o seu grupo de se implantar onde ele quiser, o tempo que ele quiser, para produzir o que ele quiser, comprando e vendendo o que ele quiser, e tendo que suportar o menor número de obrigações possíveis em matéria de direito do trabalho e de convenções sociais". (CHENAIS, 1997, p. 22 apud HIRATA, 2001/02, p. 142). 


\section{tempordilis}

ficado que os homens representam $61,1 \%$ da população ocupada no Brasil. A própria pesquisa ressalta que as mulheres são aquelas que apresentam maioria na população em idade para trabalhar, todavia a predominância da ocupação é masculina. Apesar do aumento da participação das mulheres no mercado de trabalho, elas ainda ocupam atividades informais e precárias. Em publicação que apresenta o panorama das relações de gênero no Brasil, o IBGE (2014) demonstra que as desigualdades entre homens e mulheres aumentaram consideravelmente, entre os anos 2000 e 2010, as mulheres receberam em média até $70 \%$ do salário dos homens. Além disso, destaca-se que não se mantém apenas as diferenças entre homens e mulheres, mas também entre as próprias mulheres no quesito raça.

As mulheres nessa realidade de precarização possibilitam ao capital uma participação enquanto sujeitos debilitáveis, já que, "[...] são menos protegidas, tanto pela legislação do trabalho quanto pelas organizações sindicais, e são mais vulneráveis" (HIRATA, 2001/02, p. 144). Essas experimentações podem ser das mais variáveis possíveis, principalmente no caso brasileiro, que tem em seu processo sócio-histórico padrões escravocratas e clientelistas, recriando relações de exploração e de submissão de diversas espécies. Em face de pesquisas sobre trabalho e desemprego em âmbito internacional, Hirata (2009, p. 26) apresenta três indicadores do trabalho precário:

1. Ausência de proteção social e de direitos sociais, inclusive de direitos sindicais: o trabalho informal nos países do Sul concerne a atividades realizadas sem proteção social (previdência social, aposentadoria), férias, etc. O mesmo ocorre com um certo número de empregos do setor de serviços nos países do Norte (trabalhadores domésticos, faxineiras, etc.);

2. Horas reduzidas de trabalho, que resultam em salários baixos e que levam frequentemente à precariedade; por exemplo, uma mulher que trabalhe em tempo parcial, mesmo tendo um contrato por tempo indeterminado, pode ser considerada como alguém que exerce um trabalho precário;

3. Níveis baixos de qualificação: a ausência de qualificação formal e a consequente baixa renda levam, em inúmeros casos, à precariedade e ao desemprego. (HIRATA, 2009, p. 26).

Para a autora, esses indicadores apontam para uma dada di- 


\section{temporollis}

visão sexual da precariedade, já que são as mulheres mais do que os homens, que vão ocupar empregos de baixa qualificação e de horas inferiores. Como as mulheres são particularmente atingidas pela precarização e a flexibilização7, é evidente que elas tendem a ocupar lugares singulares na divisão social do trabalho, como o comércio e o setor de serviços. Hirata (2011), destaca dois setores que se encontram em expansão e que absorvem as mulheres de forma massiva, e que por vezes são temporários, com baixos salários e relativamente limitados ao tempo, são eles: telemarketing ${ }^{8}$ e o care.

Cabe destacar que o trabalho do care tem levantado questões e estimulado pesquisas no campo das Ciências Sociais, principalmente à Sociologia de Gênero. Hirata (2009) descreve algumas questões que envolvem o trabalho do cuidado, afirmando que "[...] a globalização do home care contribui fortemente hoje em dia para trazer para a esfera pública questões anteriormente atinentes apenas à esfera privada, até mesmo a intimidade". E ao trazer para a esfera da produção questões que ficavam restritas ao espaço reprodutivo, possibilita desvendar e problematizar duas importantes questões:

1-Torna-se atual a questão do reconhecimento das qualidades ditas femininas (o 'cuidado' com o outro, a competência relacional) enquanto competência profissional. [...] Os homens possuem qualificações, as mulheres 'qualidades', consideradas naturais, inatas, na medida em que não foram adquiridas pela formação profissional; 2 - Levar a reconhecer, na esfera pública, o trabalho realizado pelas mulheres na esfera privada e, consequentemente, transformar trabalho doméstico em trabalho mercantil eventualmente efetuado em um âmbito misto, também por homens -, reconhecimento tanto social quanto financeiro. (HIRATA, 2009, p. 32).

Além da precarização e da flexibilização enquanto consequências da reestruturação produtiva se assistem, em relação ao trabalho feminino, a sua bipolarização. São identificadas pela autora duas ten-

7 "A flexibilidade do trabalho repousa sobre níveis variáveis, mas sempre presentes, de rigidez nos comportamentos sociais. Entre esses fatores de rigidez, a divisão sexual do trabalho é central. Paradoxalmente, ela possibilita a organização flexível do trabalho: o trabalho assalariado das mulheres, principalmente sob a forma de trabalho em tempo parcial compulsório, e o trabalho assalariado dos homens, possibilitado pelo trabalho doméstico das mulheres". (CATTANÉO; HIRATA, 2009, p. 109).

8 Para maior aprofundamento buscar Nogueira (2011). 
dências dessa evolução que também representam o resultado de um duplo processo de desigualdade social expressa nas relações antagônicas, principalmente entre as próprias mulheres:

1- De um lado, estabelece-se um pólo constituído por mulheres executivas de profissões intelectuais superiores, categorias que se feminizam (médicas, advogadas, juízas, arquitetas, jornalistas, professoras universitárias, pesquisadoras, assalariadas do ramo da publicidade e da arte, etc.); 2- Do outro, mulheres que se mantém nas ocupações tradicionalmente femininas: funcionárias públicas, da saúde, da educação, dos serviços aos particulares, auxiliares de enfermagem, enfermeiras, professoras primárias, profissionais do home care - que atendem pessoas idosas, doentes, crianças, e que fazem o trabalho doméstico como empregadas, faxineiras, etc. (HIRATA, 2009, p. 30).

Fica evidente na bipolarização o corte de classe em relação ao trabalho feminino. Tendo como consequência desse fenômeno a feminização da pobreza, em que as formas de organizar as delegações dos cuidados atribuídos às mulheres se dão de formas distintas, aquelas que podem pagar por um profissional de "serviços" transferem suas tarefas domésticas e, assim, têm a possibilidade de ocupar e ascender na escala profissional e construir uma carreira.

É importante destacar como esse fenômeno da submissão e desigualdade entre as mulheres, na realidade brasileira, é reatualizado. ${ }^{9}$ Cabe recordar que nos primeiros anos da industrialização, no início do século XX, as mulheres negras (as ex-escravas) foram trabalhar nas casas das famílias de classe média e rica dedicando-se à prestação de serviços domésticos; as mulheres de classe média poderiam optar em ser professoras, enfermeiras, entre outras atividades; e, as mulheres pobres direcionavam-se para as indústrias. Assim, torna-se necessário atentarmos para os processos sócio-históricos que permeiam a divisão sexual do trabalho e reafirmam a desigualdade, a submissão e

9 "Para o exercício de atividades fora do espaço doméstico, é trivial que as mulheres precisem delegar tarefas da administração de suas casas a outras mulheres. No caso brasileiro, essas são práticas de longa duração histórica que reafirmam a maternidade transferida, forma de as mulheres atribuírem-se mútuas responsabilidades, legitimada nas lutas feministas. Essa transferência atualiza desigualdades seculares nos acessos das mulheres a direitos sociais, próprias das relações de poder e subordinação que presidem a montagem dos sistemas protecionistas" (COSTA, 2002, p. 303-304). 


\section{temporollis}

a exploração das mulheres em relação aos homens e em relação com elas mesmas, principalmente no caso brasileiro.

\section{Gênero e care}

O care em português significa cuidado, preocupação com o outro, desvelo, diligência, atenção. ${ }^{10}$ Apesar de permanecer por muito tempo escondido nas relações privadas e enquanto atributo das muIheres ${ }^{11}$, o care tem ocupado a agenda política e também os debates acadêmicos nos últimos anos.

Com a inserção das mulheres de forma intensa no mercado de trabalho torna-se necessário pensar estratégias para a promoção do cuidado às crianças, aos idosos, aos doentes e a outros sujeitos que precisam de cuidados diários e permanentes. A provisão desse cuidado na esfera reprodutiva sempre foi um atributo feminino, e por isso uma função, só que, com as novas configurações no mundo do trabalho, essas mulheres vão ocupar a esfera produtiva e não há quem promova esses cuidados a não ser que sejam outras mulheres convocadas a assumirem esse lugar.

\section{O care - o cuidado com o outro - não é algo novo: o cuidar das}

10 "No Brasil e nos países de língua espanhola, a palavra cuidado é usada para designar a atitude; mas é o verbo cuidar, designando a ação, que parece traduzir melhor a palavra care. Assim, se é certo que cuidado, ou atividade do cuidado, ou mesmo ocupações relacionadas ao cuidado, como substantivos, foram introduzidos mais recentemente na língua corrente, as noções de "cuidar" ou de "tomar" conta com vários significados, sendo expressões de uso cotidiano. Elas designam, no Brasil, um espectro, de ações plenas de significado nativo, longa e amplamente difundidas, muito embora difusas no seu significado prático. O "cuidar da casa" (ou "tomar conta da casa"), assim como o "cuidar das crianças" (ou "tomar conta das crianças") ou até mesmo o "cuidar do marido", ou "dos pais", têm sido tarefas exercidas por agentes subalternos e femininos, os quais (talvez por isso mesmo) no léxico brasileiro têm estado associados à submissão, seja dos escravos (inicialmente), seja das mulheres, brancas ou negras (posteriormente)." (GUIMARÃES; HIRATA; SUGITA, 2011, p. 154).

11 "A história social brasileira tem revelado nexos pouco examinados entre padrões de domesticidade e pautas feministas de lutas por direitos sociais. Em certas conjunturas, essas pautas reafirmaram obrigações femininas nas casas, múltiplas práticas de proteção social de crianças e adultos, doentes físicos e mentais, de natureza primária - família e grupos de convívio -, dispensando ou retardando a montagem da proteção social secundária no país: serviços sociais em instituições estatais e privadas de cuidados diversos." (COSTA, 2002, p. 301). 
crianças, os afazeres domésticos e a organização da casa, a prestação de cuidados para a saúde do idoso, ou seja, atividades que pertencem à vida cotidiana, ao longo do tempo foram profissionalizadas. A promoção do bem-estar foi mercantilizada, sendo expressa por múltiplas profissões: babás, empregadas domésticas, faxineiras, no campo da saúde com a técnica e auxiliar de enfermagem e outras atividades.

Entretanto, "[...] o que é novo em relação ao care é a inclusão de mais uma ocupação no arcabouço dos cuidados - o/a cuidador/a de idoso", ou seja, nessa ocupação há uma nebulosa relação de trabalho. Apesar da análise e da pesquisa das autoras estarem direcionadas para o campo da gerontologia, a profissionalização e a expansão do care tem se dado por múltiplas demandas da própria sociedade, devido às reconfigurações das famílias, a saída das mulheres para o mercado de trabalho e as demandas das políticas públicas. (HIRATA; GUIMARÃES, 2013, p. 336).

Hirata (2010, p. 48) aponta que se fosse para retratar uma definição do care de forma mais rigorosa, ela seria o "[...] tipo de relação social que se dá tendo como objeto outra pessoa". A promoção do cuidado pode ser estabelecida de muitas formas, o que nos impossibilita de caracterizar uma dada forma de cuidar: cozinhar para a outra pessoa é care, já que, está alimentando-a; dar banho é care; dar água é care. Os atos de cuidar podem ser múltiplos, o que diferencia essa forma de operar o cuidado é a sua mercantilização que demarca a hierarquia, a formação, a remuneração, as condições de trabalho, etc.

É preciso considerar que não há apenas uma definição de care; ela é multidimensional para abarcar o 'amplo campo de ações e atitudes' e as diversas hierarquias existentes em seu interior, em termos de profissionalização (formação, remuneração, recrutamento, promoção, condições de trabalho, reconhecimento etc.) e prestígio: cuidadoras da primeira infância, babás, empregadas domésticas e diaristas, técnicas e auxiliares de enfermagem, e agora, a nova figura de cuidadora ou profissional do care, que, no Brasil, por exemplo, ainda não se reconhece como tal. Para alguns, 'existe um continuum entre cuidados médicos, os trabalhos dos cuidadores e o trabalho doméstico, pois todos contribuem para a promoção da saúde.' (HIRATA; GUIMARÃES, 2013, p. 371).

Guimarães, Hirata e Sugita (2011) destacam que para avançar na identificação das múltiplas construções de modalidade do care, é 


\section{temporollis}

primordial observar "[...] as maneiras como o mercado [...] e as políticas públicas influenciam nesse processo, e como diferentes agentes sociais se constituíram no seu curso" (p. 155). A emergência dessa ocupação ocorre pelas transformações econômicas, políticas e sociais que, não só o Brasil vem sofrendo, mas também em outras realidades.

Para finalizar, cabe destacar, que na realidade brasileira o termo cuidador apareceu com a introdução da nova Classificação Brasileira de Ocupações (CBO) nos anos 2000. De acordo com as instruções da $\mathrm{CBO}^{12}$ a formação necessária para os cuidadores de crianças, jovens, adultos e idosos ${ }^{13}$ é de cursos livres com carga horária de 80/160 horas, com idade mínima de 18 anos e ensino fundamental completo.

A atuação desse profissional se realiza em instituições públicas e/ou privadas, além de domicílios. As atividades executadas dividem-se em sete grandes eixos: cuidar da pessoa; cuidar da saúde da pessoa; promover o bem-estar da pessoa; cuidar da alimentação da pessoa; cuidar do ambiente domiciliar e institucional; incentivar a cultura e a educação; acompanhar a pessoa em atividades externas (passeios, viagens, férias). Assim, fica evidente a amplitude da atribuição dessa ocupação e a não exigência de uma formação específica acerca da promoção de um dado cuidado que vem sendo exercidos de acordo com as "qualidades" e atributos que seriam específicos do gênero feminino.

\section{Considerações finais}

Apesar de a temática não se esgotar neste artigo, é importante sinalizarmos os limites existentes do trabalho do care em face das transformações do mundo do trabalho e da reestruturação produtiva, compreendendo conforme a relação dialética posta pela contradição da ordem burguesa, os impactos gerados no sistema de gênero e na reafirmação das desigualdades sociais.

Partimos da premissa de que o trabalho doméstico remunerado e não remunerado compõe o conceito ampliado de trabalho re-

12 Informações obtidas em consulta ao site do Ministério do Trabalho e Emprego. (BRASIL, 2015).

13 O código de cadastro da ocupação é 5162. Dentro dessa ocupação tem as subclassificações que particularizam as ações: 5162/05 - Babá; 5162/10 - Cuidador de idosos; 5162/15 - Mãe social; 5162/20 - Cuidador em saúde. Os técnicos e auxiliares de enfermagem não compõem essa ocupação, localizam-se na ocupação 3222. 
tratado por Hirata e Kergoat, compreendendo que as relações sociais sexuais e a divisão sociossexual do trabalho constituem um sistema de gênero que é perpetuado tanto na esfera produtiva quanto na esfera reprodutiva. Portanto, as desigualdades instaladas na sociedade de classe também são produtos do sistema de gênero.

Com as mudanças no cenário produtivo, o capital transformase e reformula-se utilizando enquanto estratégia a precarização e a flexibilização dos vínculos empregatícios e das condições de trabalho. Nesse cenário, as mulheres são (con)vocadas a ocuparem trabalhos precarizados e subalternizados, o que possibilitou um aumento do lucro para o capital, já que elas recebem menos do que os homens e necessitam de horários flexíveis para promoverem o cuidado no espaço doméstico. Logo, para o mercado tornou-se imprescindível a participação das mulheres no que se refere à busca desenfreada da maximização do capital, uma vez que seus trabalhos são flexíveis, precários e subalternos.

Com tais mudanças, houve a ampliação do setor de serviços que possibilitou a mercantilização de atividades que eram executadas por mulheres na esfera reprodutiva, especificamente enquanto atributo feminino. As atividades direcionadas ao cuidado tornaramse mercadorias que podem ser vendidas e comercializadas, por meio da prestação de serviços. Cabe assinalar que características anteriormente fixadas em um padrão de normas e valores enquanto atributo feminino, nesse cenário, é capturado para a extração do lucro, tornando-se uma competência profissional "natural".

Apesar da (con)vocação das mulheres para exercerem o trabalho do cuidado, não há uma exigência de qualificação profissional, ficando elas restritas a qualidades ditas "naturais" do gênero feminino proporcionando a desqualificação e a precarização das mulheres. As mulheres pobres e sem formação são as mais afetadas e as mais (con)vocadas nessa realidade, pois, acabaram ocupando as atividades direcionadas para a promoção do cuidado, seja para as crianças, para os idosos, para os deficientes e demais pessoas que dele necessitarem. No caso brasileiro, são as mulheres pobres e negras que atuam enquanto trabalhadoras do care, portanto, tem-se não apenas a reprodução da desigualdade de gênero, mas a perpetuação da desigualdade de classe e de raça também.

Assim, deixamos indagações para serem pensadas acerca das 


\section{temporollis}

novas facetas postas pelo mercado, onde não só os homens são atingidos, especificamente com o aumento do desemprego, mas as muIheres são componentes fundamentais para a perpetuação da extração do lucro, ao mesmo tempo em que elas são inseridas no mercado de trabalho, elas sofrem com a precarização, com a flexibilização e com a subalternidade advindas das diferenças de gênero, e também no caso brasileiro, com a diferença de raça.

Referências

ANTUNES, R. Os sentidos do trabalho: ensaio sobre a afirmação e a negação do trabalho. São Paulo: Boitempo, 1999.

. Adeus ao trabalho?: ensaio sobre as metamorfoses e a centralidade do mundo do trabalho. 12. ed. São Paulo: Cortez, 2007.

. Desenhando a nova morfologia do trabalho: as múltiplas formas de degradação do trabalho. Revista Crítica de Ciências Sociais, Coimbra, n. 83, p. 19-34, dez. 2008.

BRASIL. Ministério do Trabalho e Emprego. Classificação brasileira de ocupações. Disponível em: http://www.mtecbo.gov.br/cbosite/ pages/pesquisas/ResultadoFamiliaHistoricoOcupacoes.jsf Acesso em: 25 set. 2015.

BRAVERMAN, H. Trabalho e capitalismo monopolista: a degradação do trabalho no século XX. Rio de Janeiro: LTC, 2012.

BRUSCHINI, M. C. A. Trabalho e gênero no Brasil nos últimos dez anos. Cadernos de Pesquisa, São Paulo, v.37, n.132, p. 537-572, set./dez., 2007.

CAMPOS, M. S.; TEIXEIRA, S. M. Gênero, família e proteção social: as desigualdades fomentadas pela política social. Revista Katalysis, Florianópolis, v. 13, n. 1, p. 20-28, jan./jun. 2010.

CATTANÉO, N.; HIRATA, H. Flexibilidade. In: HIRATA, H. (Org.). Dicionário crítico do feminismo. São Paulo: Editora UNESP, 2009.

COSTA, S. G. Proteção social, maternidade transferida e lutas pela saúde reprodutiva. Estudos Feministas, Florianópolis, v. 10, n. 2, p. 301- 
324, 2002.

GUIMARÃES, N. A.; HIRATA, H. S.; SUGITA, K. Cuidado e cuidadoras: o trabalho do care no Brasil, França e Japão. Sociologia \& Antropologia, Rio de Janeiro, v. 1, p. 151-180, 2011.

HELLER, A. Teoria de las necessidades en Marx. Barcelona: Ed. Península: 1986.

HIRATA, H. S. Globalização e divisão sexual do trabalho. Cadernos Pagu, Campinas, n. 17/18, p. 139-156, 2001/2002.

. Reestruturação produtiva, cidadania e gênero. In: COSTA, A. A. (Org.) Um debate crítico a partir do feminismo: reestruturação produtiva, reprodução e gênero. São Paulo: CUT/Brasil, 2002.

. (Org.). Dicionário crítico do feminismo. São Paulo: Editora $\overline{\mathrm{UNESP}}$, 2009.

- Tendências recentes da precarização social e do trabalho: Brasil, França, Japão. Caderno CRH, Salvador, v. 24, n. esp. 1, p. 15-22, 2011.

- Teorias e práticas do CARE: estado sucinto da arte, dados de pesquisa e pontos em debate". In: FARIA, N.; MORENO, R. (Orgs.). Cuidado, trabalho e autonomia das mulheres. São Paulo: SOF, 2010. (Coleção Cadernos Sempreviva, Série Economia e Feminismo 2).

; GUIMARÃES, N. A. Cuidado e cuidadoras: as várias faces do trabalho do care. Cadernos de Pesquisa, Campinas, v. 43, n.148, p. 366-377, jan./abr., 2013.

; KERGOAT, D. Novas configurações da divisão sexual do trabalho. Cadernos de Pesquisa, Campinas, v. 37, n.132, p. 595-609, 2007.

IBGE. Instituto Brasileiro de Geografia e Estatística. Estatísticas de gênero: uma análise dos resultados do censo demográfico de 2010. Estudos \& Pesquisas: informação demográfica e socioeconômica n. 33. Rio de Janeiro: Ministério do Planejamento, Orçamento e Gestão, 2014.

KERGOAT, D. Relações sociais de sexo e divisão sexual do trabalho. In: LOPES, M. J. M.; MEYER, D. E.; WALDOW, V. R. (Orgs.). Gênero e 


\section{temporolis}

saúde. Porto Alegre: Artes Médicas, 1996.

. Divisão sexual do trabalho e relações sociais de sexo. In: HI$\overline{R A T A}$ H. (Org.). Dicionário crítico do feminismo. São Paulo: Editora UNESP, 2009.

LAZZARECHI, N. Flexibilização, desregulamentação e precarização das relações de trabalho. Revista Labor, Fortaleza, v. 13, n. 1, p. 82102, 2015. Disponível em: < http://www.revistalabor.ufc.br/Artigo/volume13/3 FLEXIBILIZACAO DESREGULAMENTACAO E\%20 PRECARIZACAO_DAS_RELACOES_DE_TRABALHO_UMA_DISTINCAO_NECESSARIA.pdf> Acesso em: 12 ago. 2015.

MARX, K. Capítulo VI: inédito de o capital (1818-1883). Tradução de Klaus Von Puchen. 2.ed. São Paulo: Centauro, 2004.

MEIRELLES, D. S. O conceito de serviço. Revista de Economia Política, São Paulo, v. 26, n. 1, p. 119-136, 2006.

MÉSZAROS, I. Marx: a teoria da alienação. Rio de Janeiro: Zahar, 1981.

NOGUEIRA, C. M. A feminização no mundo do trabalho. Campinas: Autores Associados, 2004.

. O trabalho duplicado: a divisão sexual no trabalho e na reprodução: um estudo das trabalhadoras do telemarketing. São Paulo: Expressão Popular, 2011.

- A precarização e a divisão sociossexual do trabalho. In: SILVA, J. F. S.; SANT'ANA, R. S.; LOURENÇO, E. A. S. (Orgs.). Sociabilidade burguesa e Serviço Social. Rio de Janeiro: Lumes Juris, 2013.

SHÜTZ, F.; MIOTO, R. C. T. O trabalho em serviços: contribuições para o debate do Serviço Social. Em Pauta, Rio de Janeiro, v. 10, n.30, p. 83-101, 2 sem. 2012. 